Fourth International Conference on Sustainable Construction Materials and Technologies

http://www.claisse.info/Proceedings.htm

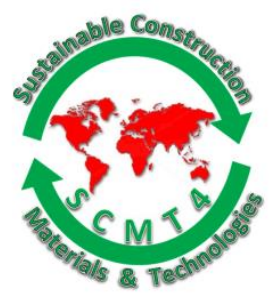

SCMT4

Las Vegas, USA, August 7-11, 2016

\title{
Use of Waste Crushed Glass for the Production of Hot-Mix Asphalt
}

\author{
Joseph K. Anochie-Boateng1, and Theresa B. George ${ }^{2}$ \\ ${ }^{1}$ Transport Infrastructure Engineering; Council for Scientific and Industrial Research (CSIR) PO Box \\ 395, Pretoria, 0001, South Africa / Civil Engineering Department, Tshwane University of Technology, \\ Private Bag X680, Pretoria 0001South Africa. \\ ${ }^{1}$ Email: <janochieboateng@csir.co.za〉. \\ ${ }^{2}$ Transport Infrastructure Engineering; Council for Scientific and Industrial Research (CSIR), ${ }^{2}$ Email: \\ <tgeorge@csir.co.za>.
}

\begin{abstract}
The Council for Scientific and Industrial Research have initiated a study to develop sustainable asphalt mixes that use locally available waste materials as an aggregate replacement to reduce the material cost while improving performance. This paper presents the development and evaluation of a new asphalt concrete mix that utilizes a sustainable crushed glass as a replacement material of a natural aggregate. The ultimate goal is to produce a cost-effective asphalt wearing course with comparative performance characteristics with a conventional asphalt wearing course (reference mix) commonly used on South African roads. The paper details the mix design process of a $9.5 \mathrm{~mm}$ nominal maximum wearing course glass asphalt with a design traffic level of 30 million ESALs. Laboratory tests were conducted on the mix, as well as on the component materials to compare results with the volumetric design criteria set in the new asphalt mix design method for South Africa. Based on the mix design, an optimum binder content of the glass asphalt mix was $5.1 \%$, which is similar to the $5.0 \%$ optimum binder content of the reference mix. Using the optimum binder content, the volumetric properties of the glass mix was analysed. The results indicate that the glass asphalt mix meets the South African criteria, thus the mix design is acceptable. The results of performance-related tests indicated that the tensile strength and durability properties of the glass asphalt mix are comparable to the reference mix.
\end{abstract}

\section{INTRODUCTION}

The use of sustainable and cost-effective alternative materials for asphalt mixes in road and airfield pavements have been recently emphasized due to potential depletion of natural aggregate sources and the increasing awareness of environmental issues i.e., green gas emissions, disposals, etc., associated with conventional asphalt materials. For instance, industrial by-products (e.g. steel slag) are gaining adoption worldwide for road construction. The South African Department of Science and Technology (DST) have set a goal of a $20 \%$ reduction (by mass) in industrial waste to landfill by 2022 . Thus, the use of waste materials for road construction is currently being promoted by the DST. On the average, 550,000 tons of waste glass finds its way into South Africa's landfills every year, while only 200,000 tons of all glass containers (glass bottles and jars) is retrieved for recycling. Substantial waste crushed glass materials are therefore, available for exploitation in South Africa. 
Waste crushed glass that is processed can be used as a portion of fine aggregate in asphalt paving mixes. Satisfactory performance has been obtained from hot mix asphalt pavements incorporating 10 to 15 percent crushed glass in wearing surface mixes [Nash et al. 1995]. The term "glasphalt" has at times been used to describe these pavements. A study by Flynn [1993] demonstrated that optimum performance can best be achieved when crushed glass is used as a fine aggregate substitute in asphalt pavements as opposed to larger sized glass particles which adversely affects pavement performance due to ravelling and stripping related problems. Furthermore, it has been demonstrated that when glass is utilised as a substitute fine aggregate in hot mix asphalt, the performance-related properties are comparable to conventional asphalt mixes [Chesner et al. 1987]. When glass was initially implemented in asphalt pavements in the early 1960's and 1970's, glass particles greater than $12.7 \mathrm{~mm}$ and quantities in excess of 25 percent by weight of mix was utilised [Recycled Materials Resource Centre - RMRC, USA]. Factors such as the lack of absorption of bitumen by glass and the hydrophilic properties of glass also contribute to the moisture damage (stripping and ravelling) experienced by glass asphalt pavements; particularly when high percentages and large particles are introduced into the surface course. Hughes [1990] revealed that addition of hydrated lime (approximately 1 to 3 percent by weight of aggregate) to mixes with glass acts as an antistripping agent and reduces potential stripping problems. The study indicated that although antistripping agent could be beneficial, however, satisfactory performance can be achieved if only finegrained glass (minus $4.75 \mathrm{~mm}$ ) is used with substitution rates not surpassing 15 percent. The benefits of utilising crushed glass in asphalt pavements include the high angularity of the crushed glass which can enhance the stability of glass asphalt mixes when compared with conventional asphalt mixes with virgin aggregates. Other favourable characteristics include low absorption, specific gravity and thermal conductivity, which enhances heat retention in mixes with glass.

In South Africa, a significant amount of crushed waste glass accumulates as stockpiles at a major glass manufacturing plant in South Africa. The waste glass forms part of the processed glass (less than 4.75 $\mathrm{mm}$ ) that cannot be used as recycled material during glass production. It was indicated that approximately 3,000 tons per month of this waste glass accumulates as stockpiles at the plant. Although the glass fines were observed to be relatively free of contaminants such as paper, plastic as well as dirt debris, an accurate quantification of the percentage of glass present in the crushed waste glass material was performed by means of an X-ray diffraction (XRD) analysis by a CSIR research group (2015). The analysis revealed that glass comprises on average more than $90 \%$ of the crushed waste material.

The objective of this paper is to present the design of hot mix asphalt that utilises a waste glass as a substitute material to a conventional aggregate. A $9.5 \mathrm{~mm}$ nominal maximum wearing course glass asphalt mix with traffic level of 30 million ESALs was designed based on a similar grading and component materials of a conventional asphalt wearing course (reference mix) used on South African roads. The procedures in the new asphalt mix design methods for South Africa was followed [AnochieBoateng et al. 2015]. Two empirical performance-related properties, i.e. durability and strength were determined to compare performance of glass asphalt with the reference mix.

\section{MATERIALS SELECTION}

\section{Aggregate Materials and Properties}

To ensure uniformity, aggregates from the same sources as the reference asphalt mix were utilised in this study. These aggregates were andesite, granite and mine sand from local quarries in the province of Gauteng. The crushed waste glass was sourced from a major glass manufacturing company in South Africa. A hydrated lime was used as filler for the mix. Each aggregate was fractionated after complete drying in an oven, and the sieved materials were stored in sealed containers to ensure quality control. The physical properties of the aggregates were determined using the South African National Standard (SANS) test methods described in SANS 3001. 
Table 1 summarizes the grading results and the physical properties of the aggregate samples. The results indicate that all aggregate materials and the crushed glass conform to specifications. Wet sieve analysis was carried out on individual aggregate fractions. The results are presented in Figure 1. The fine aggregate angularity (FAA) test [ASTM C1252] was performed on all aggregate fractions purposely to compare angularity of the crushed glass with the conventional aggregate materials. The results (Table 1) shows that the crushed glass are more angular than the crusher sand, crusher dust and mine sand aggregate fractions.

Table 1. Aggregates Used in the Mix Design

\begin{tabular}{|c|c|c|c|c|c|c|c|c|}
\hline $\begin{array}{l}\text { Aggregate } \\
\text { Property }\end{array}$ & Aggregate Type & $\begin{array}{l}\text { Andesite } \\
9.5 \mathrm{~mm}\end{array}$ & $\begin{array}{l}\text { Andesite } \\
6.7 \mathrm{~mm}\end{array}$ & $\begin{array}{c}\text { Andesite } \\
\text { Crusher } \\
\text { Dust }\end{array}$ & $\begin{array}{c}\text { Granite } \\
\text { Crusher } \\
\text { Sand }\end{array}$ & $\begin{array}{l}\text { Mine } \\
\text { Sand }\end{array}$ & $\begin{array}{c}\text { Waste } \\
\text { Crushed } \\
\text { Glass }\end{array}$ & $\begin{array}{l}\text { Filler } \\
\text { (Lime) }\end{array}$ \\
\hline \multirow{11}{*}{ 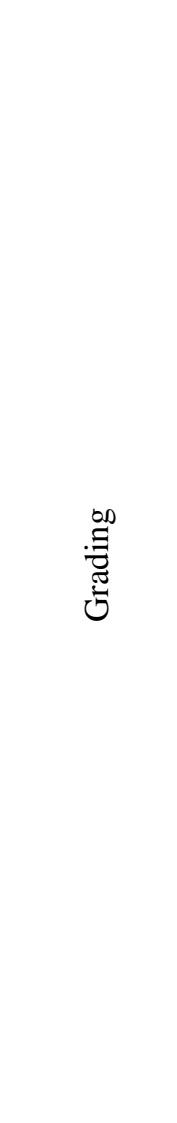 } & $19.0 \mathrm{~mm}$ & 100 & 100 & 100 & 100 & 100 & 100 & 100 \\
\hline & $13.2 \mathrm{~mm}$ & 100 & 100 & 100 & 100 & 100 & 100 & 100 \\
\hline & $9.5 \mathrm{~mm}$ & 91 & 100 & 100 & 100 & 100 & 100 & 100 \\
\hline & $6.7 \mathrm{~mm}$ & 26 & 86 & 99 & 100 & 100 & 100 & 100 \\
\hline & $4.75 \mathrm{~mm}$ & 4 & 34 & 98 & 99 & 100 & 100 & 100 \\
\hline & $2.36 \mathrm{~mm}$ & 1 & 3 & 61 & 70 & 100 & 91 & 100 \\
\hline & $1.18 \mathrm{~mm}$ & 1 & 2 & 37 & 45 & 100 & 50 & 100 \\
\hline & $0.6 \mathrm{~mm}$ & 1 & 2 & 23 & 25 & 99 & 23 & 100 \\
\hline & $0.3 \mathrm{~mm}$ & 1 & 2 & 16 & 13 & 82 & 11 & 100 \\
\hline & $0.15 \mathrm{~mm}$ & 1 & 2 & 11 & 5 & 34 & 5 & 100 \\
\hline & $0.075 \mathrm{~mm}$ & 0.4 & 1.4 & 8.3 & 1,5 & 8.1 & 2.8 & 99 \\
\hline \multirow{3}{*}{ 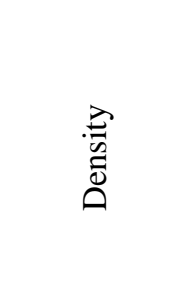 } & $\begin{array}{l}\text { Bulk Relative } \\
\text { Density }\end{array}$ & 2.884 & 2.887 & 2.816 & 2.628 & 2.600 & 2.489 & 2.861 \\
\hline & $\begin{array}{c}\text { Apparent } \\
\text { Relative Density }\end{array}$ & 2.919 & 2.928 & 2.956 & 2.676 & 2.634 & 2.519 & -- \\
\hline & Absorption & 0.4 & 0.5 & 1.7 & 0.7 & 0.5 & 0.5 & -- \\
\hline $\begin{array}{c}\text { Sand } \\
\text { Equivalent }\end{array}$ & Criteria $\geq 50$ & N/A & N/A & 69 & 77 & 56 & 74 & -- \\
\hline $\begin{array}{c}\text { Fine } \\
\text { Aggregate } \\
\text { Angularity }\end{array}$ & $\begin{array}{c}\text { Superpave } \\
\text { Criteria ( } 45 \text { min, } \\
30 \text { MESALs) }\end{array}$ & N/A & N/A & 39.7 & 38.3 & 48.3 & 51.3 & -- \\
\hline
\end{tabular}




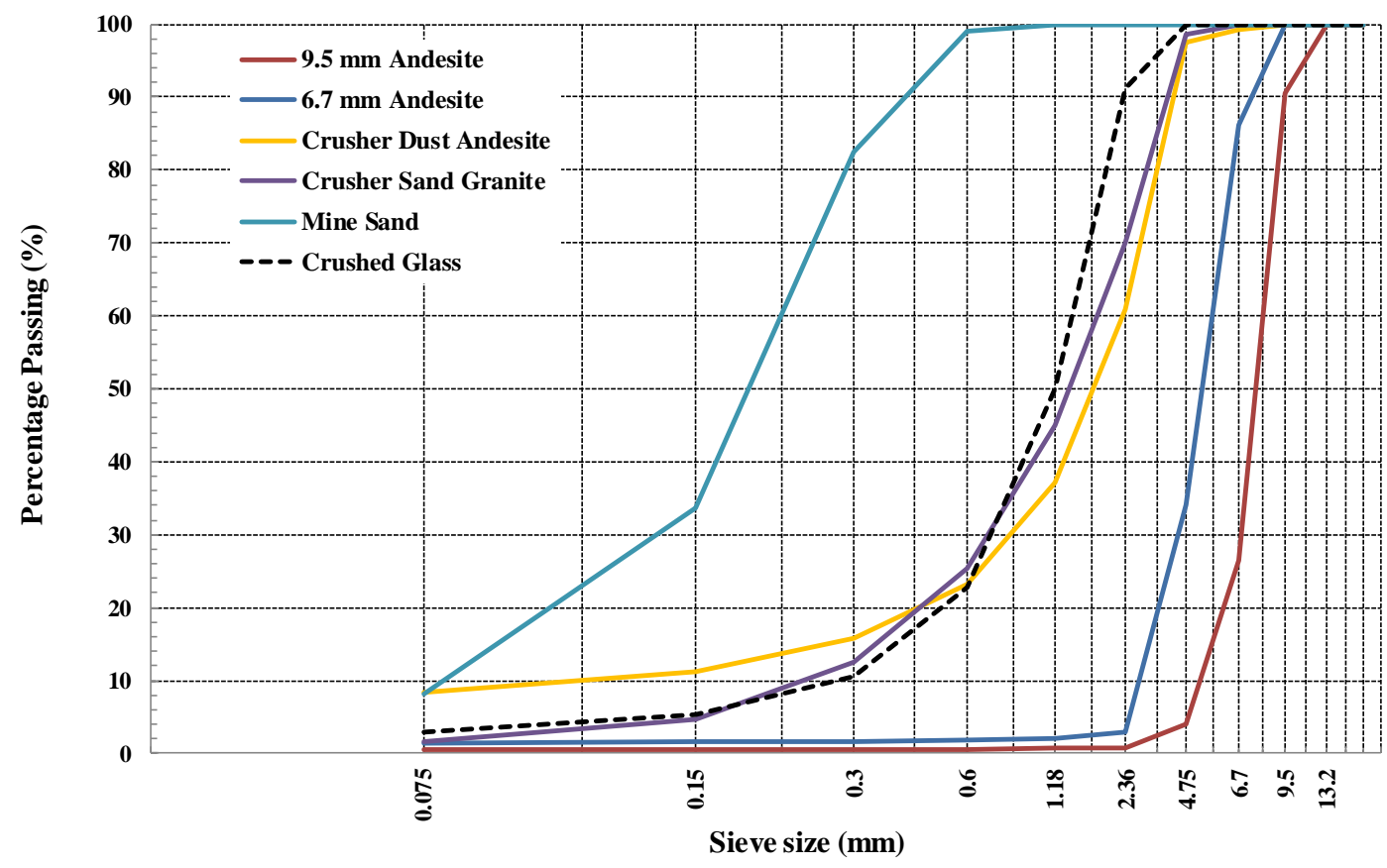

Figure 1. Particle Size Grading Distribution of Aggregate Materials

\section{Scanning Electron Microscopy}

In addition, to the physical properties determined for the crushed glass, a microscopic morphology was determined by Scanning Electron Microscopy (SEM) to illustrate the angularity of the crushed glass in the mix. The results are shown in Figure 2. The SEM examinations also revealed that the crushed glass mainly consisted of angular flaky particles with a broad range of particle sizes.

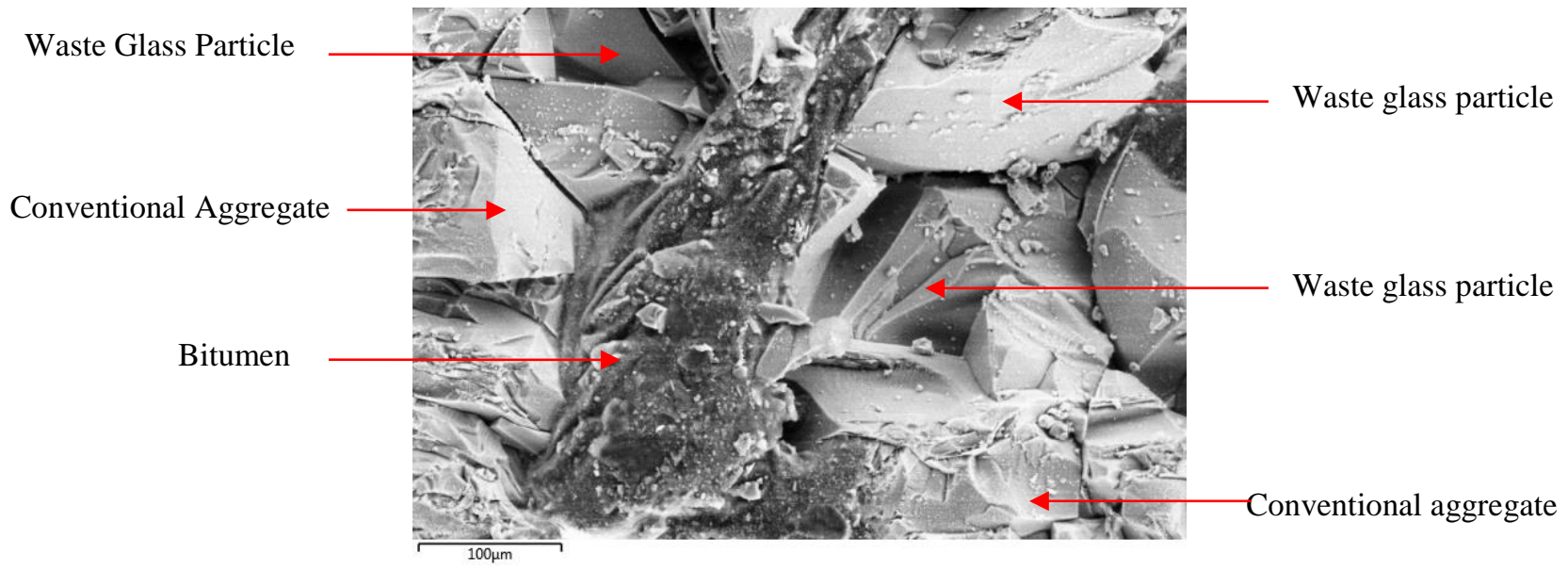

Figure 2. SEM Micrograph of Crushed Waste Glass

\section{Bituminous Binder and Properties}

A 50-70 penetration grade binder was used for the study. The binder was sourced from a petroleum refinery in South Africa and was supplied by an asphalt manufacturing plant. Table 2 presents the summary of the various properties of the 50-70 penetration grade binder as tested by the petroleum refinery company. All criteria were met by the selected binder for an asphalt mix design. 
Table 2. Properties of the 50-70 Penetration Grade Bitumen

\begin{tabular}{|l|c|c|c|c|}
\hline Property & Units & Limits & Results & Test Method \\
\hline Penetration @ $25^{\circ} \mathrm{C} / 100 \mathrm{~g} / 5 \mathrm{sec}$ & $0.1 \mathrm{~mm}$ & $50-70$ & 66 & ASTM D5 \\
\hline Softening Point (Ring \&Ball) & degC & $46-56$ & 50 & ASTM D36 \\
\hline Viscosity @ 60 $0^{\circ} \mathrm{C}$ & Pa.s & $120 \mathrm{~min}$ & 261 & ASTM D4402 \\
\hline Viscosity @ $135^{\circ} \mathrm{C}$ & $\mathrm{mPa} . \mathrm{s}$ & $220-500$ & 469 & ASTM D4402 \\
\hline Flash Point (Open Cup) @ 101.3 kPa & degC & $230 \mathrm{~min}$ & 340 & ASTM D92 \\
\hline Spot Test & \% Xylene & $30 \mathrm{max}$ & 25 & AASHTO T102 \\
\hline \multicolumn{2}{|c|}{ Properties after Rolling Thin Film Ageing Test } \\
\hline Mass Change & Mass 5 & $0.3 \mathrm{max}$ & +0.09 & ASTM D2872 \\
\hline Viscosity @ 60 ${ }^{\circ} \mathrm{C}$ & \% Original & $300 \mathrm{max}$ & 236 & ASTM D4402 \\
\hline Softening Point (Ring \&Ball) & degC & $48 \mathrm{~min}$ & 55 & ASTM D36 \\
\hline Increase in Softening Point & degC & 7 max & 5 & ASTM D36 \\
\hline Retained Penetration & 5 Original & $55 \mathrm{~min}$ & 65 & ASTM D5 \\
\hline
\end{tabular}

\section{GLASS ASPHALT MIX DESIGN}

\section{Design Aggregate}

The reference mix was composed of the $21 \%$ of $9.5 \mathrm{~mm}$ andesite, $24 \%$ of $6.7 \mathrm{~mm}$ andesite, $25 \%$ of crusher dust, $26 \%$ of crusher sand, $3 \%$ of mine sand, and $1 \%$ of plant filler. The grading of the individual aggregate fractions (Figure 1) was the basis for the selection of the substitute glass in the reference mix. The grading for the crushed waste glass is closer to the granite crusher sand than any other material. The granite crusher sand was hence, partially substituted by $15 \%$ of the glass. The combined grading was thereafter optimized to obtain the design grading for the glass asphalt mix. The goal was obtained the percentage blend of aggregates to represent a similar particle size distribution to that of the reference mix. This was achieved by optimization based on the least square analysis method in Microsoft Excel ${ }^{\mathrm{TM}}$.

Table 3 shows the percentage blends of each aggregate type and the filler required to achieve the design grading for the glass mix. To achieve the desired bonding effect between the crushed glass and the binder, $3 \%$ hydrated lime was chosen to replace $1 \%$ of the plant lime in the reference mix. As mentioned earlier, 1 to 3 percent of hydrated lime could acts as an antistripping agent and reduces potential stripping problems in asphalt mixes with glass. Figure 3 shows that the design aggregate satisfy the criteria set forth in the new asphalt mix design method for South Africa for a $9.5 \mathrm{~mm}$ nominal maximum particle size, and lies within the control points plotted in 0.45 power chart [(Anochie-Boateng et al. 2015)].

Table 3. Design Aggregate Blend for the Glass Asphalt Mix and Grading

\begin{tabular}{|c|c|c|c|c|c|c|}
\hline \multirow{2}{*}{$\begin{array}{l}\text { Nominal size } \\
(\mathrm{mm})\end{array}$} & \multirow{2}{*}{$\begin{array}{l}\text { Aggregate } \\
\text { Type }\end{array}$} & \multirow{2}{*}{$\begin{array}{c}\text { Mix } \\
\text { Proportion }\end{array}$} & \multirow{2}{*}{$\begin{array}{l}\text { Sieve Size } \\
\quad(\mathrm{mm})\end{array}$} & \multirow{2}{*}{$\begin{array}{c}\text { Design Grading } \\
\text { (\% Passing) }\end{array}$} & \multicolumn{2}{|c|}{ Grading Specification } \\
\hline & & & & & $\operatorname{Min}(\%)$ & $\operatorname{Max}(\%)$ \\
\hline 9.5 & Andesite & $31 \%$ & 13.2 & 100 & 100 & 100 \\
\hline 6.7 & Andesite & $16 \%$ & 9.5 & 97 & 82 & 100 \\
\hline Crusher dust & Andesite & $18 \%$ & 6.7 & 75 & 66 & 87 \\
\hline Crusher Sand & Granite & $10 \%$ & 4.75 & 59 & 54 & 75 \\
\hline Mine Sand & Mine Sand & $7 \%$ & 2.36 & 42 & 35 & 50 \\
\hline Crushed Glass & Glass & $15 \%$ & 1.18 & 29 & 27 & 42 \\
\hline Mineral Filler & Hydrated Lime & $3 \%$ & 0.6 & 21 & 18 & 32 \\
\hline & & & 0.3 & 15 & 11 & 23 \\
\hline & & & 0.15 & 9 & 7 & 16 \\
\hline & & & 0.075 & 6.0 & 4 & 10 \\
\hline
\end{tabular}




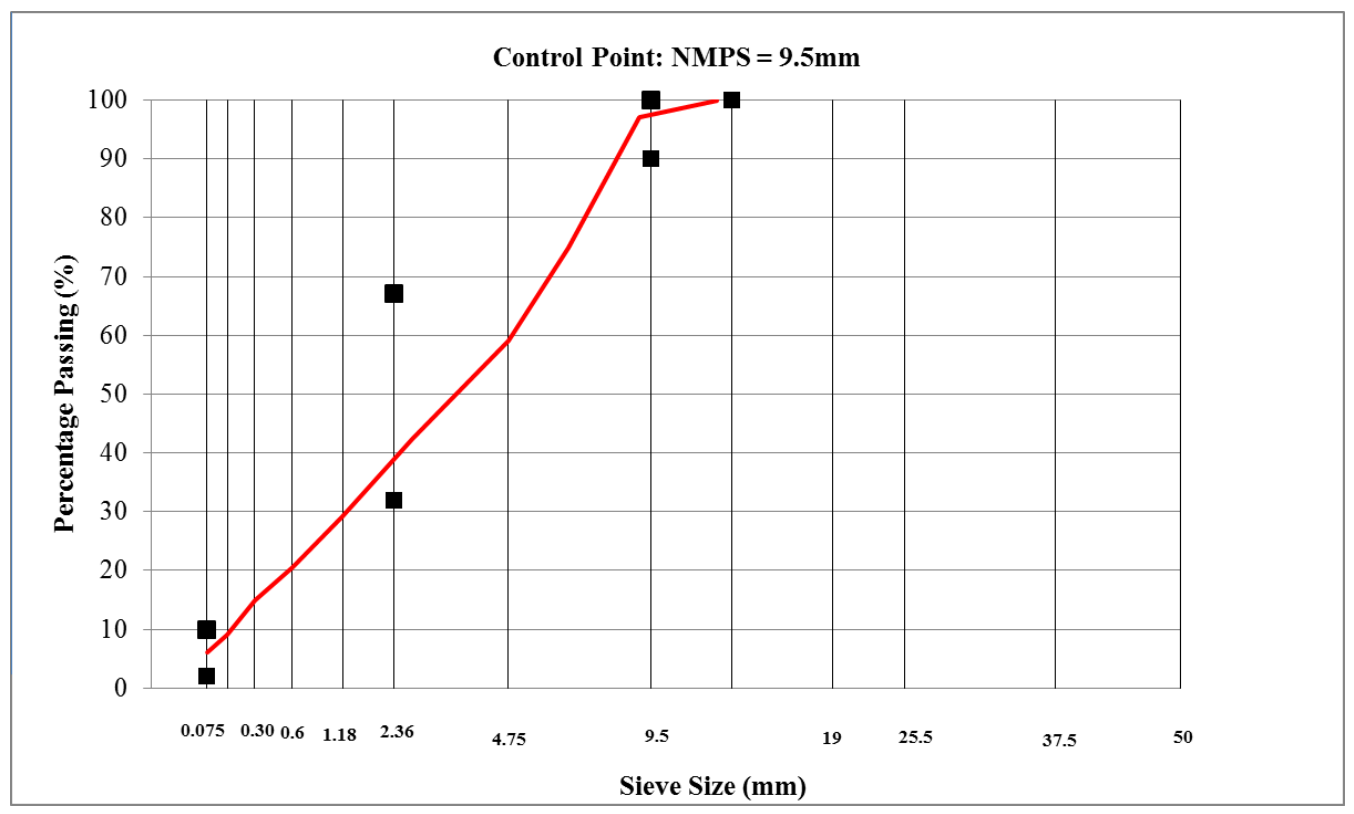

Figure 3. Design Grading of the Glass Mix on 0.45 Power Graph with Control Points

\section{Optimum Glass Asphalt Mix}

The following basic steps were followed to determine the optimum design of the glass asphalt mix:

i. Four trial binder contents were selected based on minimum binder content, the minimum $+0.5 \%$, the minimum $+1.0 \%$, and the minimum $+1.5 \%$ by mass of the total mix.

ii. Three duplicate glass asphalt mixes were prepared for each trial binder using the design aggregate grading.

iii. Two specimens for each trial mix (loose samples) were prepared to determine the maximum theoretical relative density (MTRD) in accordance to SANS 3001-AS11.

iv. Three duplicate gyratory compacted specimens $(150 \mathrm{~mm}$ in diameter by $115 \mathrm{~mm}$ in height) were prepared for each trial binder following the test procedures contained in AASHTO T 312.

v. To determine the volumetric properties of the compacted specimens, bulk relative density (BRD) tests were conducted on the compacted samples in accordance with SANS 3001-AS10.

vi. Volumetric properties of the compacted specimens, i.e. voids in the mix (VIM), voids in the mineral aggregate (VMA) and voids filled with binder (VFB) were determined.

vii. The volumetric data were used to generate graphs of VIM, VMA and VFB versus the four trial binder contents.

\section{Minimum Binder Content}

The minimum binder content for the glass asphalt mix was determined using richness modulus, specific surface area and the relative density of the design (combined) aggregates. Richness modulus (K) is a measure of the binder film thickness surrounding the aggregate, and is a proportional value related to the thickness of the binder film coating the aggregate. Equation 1 yields the required minimum binder content based on these properties:

$$
B_{p p c}=K \times \alpha \times \sqrt[5]{S A}
$$

$B_{p p c}=$ mass of binder expressed as a percentage of the total dry mass of aggregate, including filler.

$B_{P P C}$ can be converted to the binder content by mass of total mix $\left(P_{B}\right)$ generally used in South Africa. 


$$
B_{p p c}=\frac{100 \times P_{B}}{\left(100+P_{B}\right)}
$$

$K=$ richness modulus - minimum $\mathrm{K}$ values are provided as 2.9 for sand skeleton mixes and 3.4 for stone skeleton mix [Anochie-Boateng et al. 2015].

$\alpha=$ correction coefficient for the relative density of the aggregate (RDA), computed as follows:

$\alpha=\frac{2.65}{R D A} \quad S A=$ specific surface area $\left(\mathrm{m}^{2} / \mathrm{kg}\right)$.

For a dense-graded asphalt mix such as the glass asphalt mix, the minimum $\mathrm{K}$ value of 2.9 is recommended [Anochie-Boateng et al. 2015]. Based on this value, the minimum binder content of $4.0 \%$ was obtained using specific surface area and relative density of the aggregates in the mix. Accordingly, four trial binder contents for the glass asphalt mix design were $4.0 \%, 4.5 \%, 5.0 \%$ and $5.5 \%$.

\section{Asphalt Sample Preparation}

The individual aggregate fractions were dried overnight in an oven at the temperature of $110^{\circ} \mathrm{C}$. Following drying, the aggregates were riffled out into approximate quantities required for compactions. Wet sieve analysis was then carried out on each fraction. The aggregates were blended in accordance with the design grading, and mixed with the binders using a laboratory mixer. The materials were mixed for approximately 5 minutes or until a uniform mixture was obtained, i.e. all aggregate particles were coated with binder [Anochie-Boateng et al. 2010]. After mixing, the material was placed in an oven set at compaction temperature for two hours to induce short-term ageing, after which the mix was compacted. The specimens were prepared using a Superpave gyratory compactor at target air void content for each test. For each trial binder, three specimens were compacted in accordance with the AASTO T 312 (2006). Based on design traffic level of 30 million ESAL, $150 \mathrm{~mm}$ in diameter and $115 \mathrm{~mm}$ in height specimens were compacted at 100 gyrations to determine the volumetric properties of the mix.

\section{VOLUMETRIC RESULTS AND DISCUSSION}

The summary of the volumetric properties and criteria for the mix design are presented in Figure 4, and shown in Table 4 and Table 5. The laboratory measured MTRD and BRD values were used to determine the volumetrics for the mix. After calculations were made, the bitumen contents were plotted against VIM, VMA, and VFB. The South African mix design method requires the mix to have $4 \%$ air voids at the optimum binder content. Using this criterion, the optimum bitumen content of 5.1\% was established for the glass asphalt mix. This value is very close to the reference mix, which has optimum binder content of $5.0 \%$. Both VMA and VFB were checked at the binder content of $5.1 \%$ to verify whether or not they meet criteria. For a nominal maximum particle size of $9.5 \mathrm{~mm}$, the VMA should be $15 \%$ minimum while the VFB ranges between $65 \%$ and $75 \%$. All criteria were met for the glass asphalt except that the VFB value was close to the upper limit.

Meeting the VFB requirements avoids less durable mixes resulting from thin films of binder on the aggregate particles. It is known that the lower limit of VFB range should always be met at $4 \%$ air voids if the VMA requirements are met. If the VFB upper limit is exceeded, then the VMA is substantially above the minimum required as observed in this case. In a situation like this, it is suggested that the mix should be re-designed to reduce the VMA in the interests of cost savings by (1) increasing the amount of material passing $0.075 \mathrm{~mm}$ fraction, and (2) changing the aggregates to incorporate material with better packing characteristics (e.g., fewer flaky aggregate particles). The use of highly angular and a rougher surface texture aggregates is also recommended. 

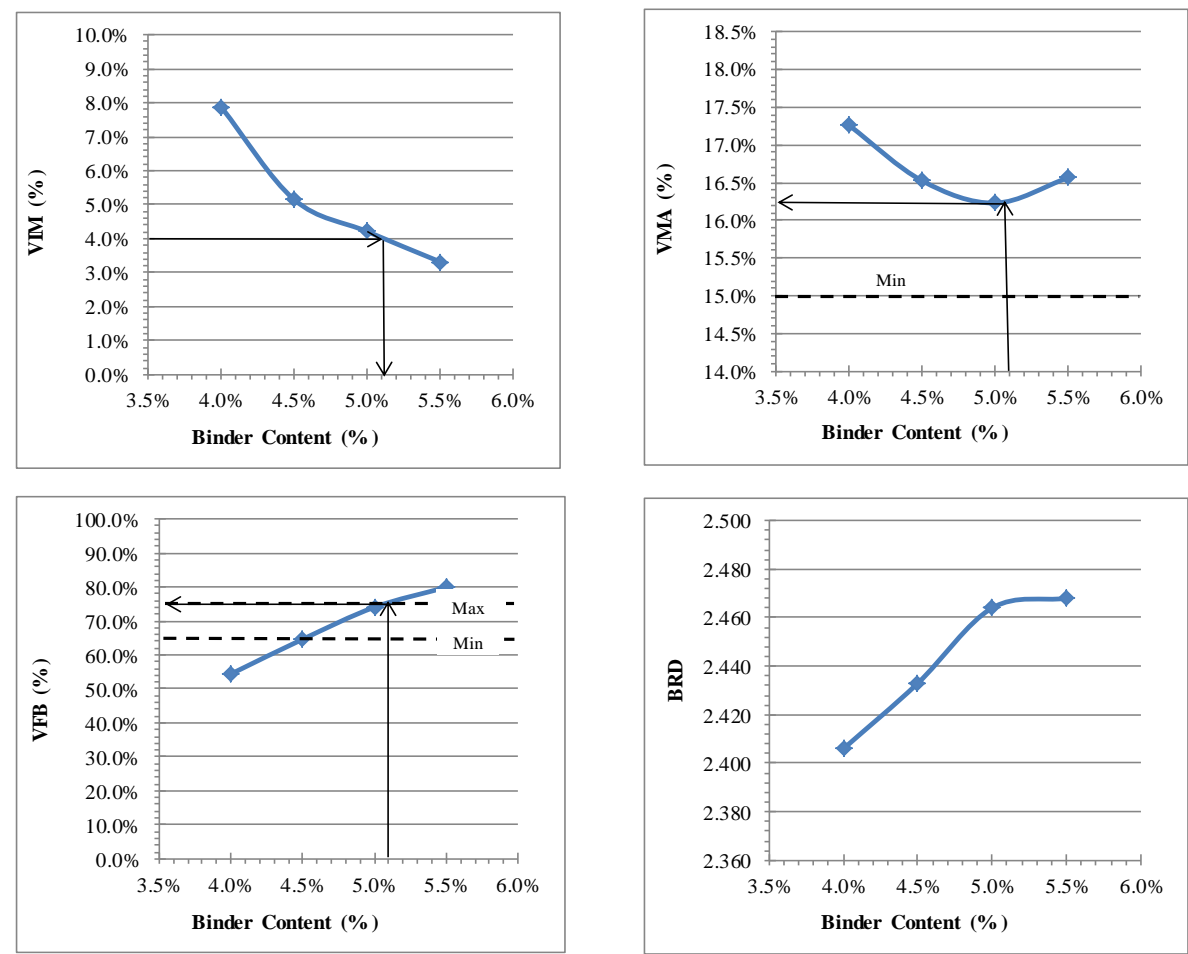

Figure 4. Optimum Binder Content and Volumetric Properties

Table 4. Volumetric Results for Glass Asphalt Mix

\begin{tabular}{|c|c|c|c|c|c|}
\hline Binder Content (\%) & MTRD & BRD & VIM (\%) & VMA 9\%) & VFB (\%) \\
\hline 4.0 & 2.612 & 2.406 & 7.9 & 17.3 & 54.4 \\
\hline 4.5 & 2.584 & 2.433 & 5.8 & 16.5 & 64.6 \\
\hline 5.0 & 2.572 & 2.464 & 4.2 & 16.2 & 74.1 \\
\hline 5.5 & 2.553 & 2.468 & 3.3 & 16.6 & 79.9 \\
\hline
\end{tabular}

Table 5. Criteria for Volumetric Properties @ Optimum Binder Content

\begin{tabular}{|c|c|c|c|}
\hline Property & Result & Criteria & Pass/Fail \\
\hline VIM & $4 \%$ & 4 & Pass \\
\hline VMA & $15.3 \%$ & Min 15 & Pass \\
\hline VFB & $74.5 \%$ & $65-75$ & Pass \\
\hline
\end{tabular}

\section{EMPIRICAL PERFORMANCE TESTING}

\section{Indirect Tensile Strength (ITS) Test}

The ITS test is commonly used to evaluate the cohesive strength of asphalt mixes. This property can be used to evaluate tensile strength (related to toughness and durability) and is also an important component of rutting resistance in the medium temperature range (i.e. $10^{\circ} \mathrm{C}$ to $30^{\circ} \mathrm{C}$ ).

In the ITS test the sample is loaded on its diametral axis. During testing, the sample is loaded at a fixed loading rate of $50 \mathrm{~mm}$ per minute until a significant loss in applied load is noted. The peak load is used to calculate the indirect tensile strength. The formula for calculation of the ITS (in kPa) is as follows: 


$$
I T S=\frac{2.0 P_{u l t}}{\pi \cdot t . D}
$$

where, $\mathrm{P}_{\text {ult }}=$ ultimate applied load, in $\mathrm{kPa} ; \mathrm{t}=$ thickness of the specimen, in $\mathrm{m}$; and $\mathrm{D}=$ diameter of the specimen, in $\mathrm{m}$

For this study, the ITS of the crushed glass determined using the AASHTO T 283 (2006) protocol. Three replicate samples were tested for the glass asphalt mix to compare with the reference mix. In comparison, the average ITS value for the glass mix was $1025 \mathrm{kPa}$ whereas the reference mix has $1140 \mathrm{kPa}$. The minimum value for ITS in South Africa is $800 \mathrm{kPa}$. However, limited field studies have suggested that rutting potential tends to increase for ITS values below approximately $1000 \mathrm{kPa}$. At the same time, ITS values in excess of $1700 \mathrm{kPa}$ may indicate a tendency to brittleness and low flexibility.

\section{Durability}

The durability of the glass asphalt mix was assessed by conducting the Modified Lottman testing (ASTM D4867M, 2009). The test was performed primarily for checking the moisture susceptibility of the glass mix. Six specimens were prepared for testing. Each specimen was compacted in a gyratory compactor to the diameter of $100 \mathrm{~mm}$ and $62.5 \mathrm{~mm}$ in height, and to a void content corresponding to typical field voids usually in range of $6 \%$ to $8 \%$. After compaction, the specimens were divided into two subsets of three specimens' with approximately equal voids content. One subset was maintained dry while the other subset was partially saturated with water and moisture conditioned. During testing, diametrical load at 50 $\mathrm{mm} / \mathrm{min}$ was applied on the specimen until the maximum loading was reached and the results recorded. The test was conducted until vertical breaks appeared on the asphalt specimen. Specimens were then removed from the apparatus and break opened to visually estimated degree of moisture damage.

The potential for moisture damage is indicated by the ratio of the tensile strength (TSR) of the wet subset to that of the dry subset. Table 6 summaries the results for the glass asphalt mix, and compared with the reference mix. The criteria for minimum TSR value for asphalt wearing courses in South Africa is 0.80 [Anochie-Boateng et al. 2015]. It can be seen that the TSR results for the glass asphalt mix and the reference mix are similar to each other, and meet the durability criteria.

Table 6. Moisture Susceptibility Results for Glass Asphalt Mix

\begin{tabular}{|c|c|c|c|c|}
\hline \multirow{2}{*}{ Parameter } & \multicolumn{2}{|c|}{ Glass Asphalt } & \multicolumn{2}{c|}{ Reference Asphalt } \\
\cline { 2 - 5 } & Wet Subset & Dry Subset & Wet Subset & Dry Subset \\
\hline Average ITS (kPa) & 721 & 845 & 808 & 946 \\
\hline TSR & \multicolumn{2}{|c|}{0.85} & \multicolumn{2}{|c|}{0.85} \\
\hline Visual moisture damage & $\begin{array}{c}\text { No moisture, } \\
\text { minor stripping }\end{array}$ & $\begin{array}{c}\text { No moisture, } \\
\text { minor stripping }\end{array}$ & $\begin{array}{c}\text { No moisture, } \\
\text { minor stripping }\end{array}$ & $\begin{array}{c}\text { No moisture, } \\
\text { minor stripping }\end{array}$ \\
\hline Cracked / broken aggregates & None & None & None & None \\
\hline
\end{tabular}

\section{CONCLUSION}

Based on the mix design results presented in this paper, the following conclusions can be made:

- The optimum binder content for the glass asphalt mix designed with the selected aggregate fractions is $5.1 \%$. 
- All volumetric properties of the glass asphalt mix comply with the criteria of the new asphalt mix design methods of South Africa. This implies that the glass asphalt mix can potentially be used as a wearing course on South Africa roads.

- The tensile strength and durability properties of the glass asphalt mix were comparable to a reference asphalt wearing course with acceptable performance results. It is likely that the glass asphalt mix can provide resistance to moisture damage and permanent deformation.

\section{ACKNOWLEDGEMENT}

Funding for this study was provided through the Parliamentary Grant by the CSIR. The authors would also like to acknowledge the glass manufacturing company in providing the waste glass material.

\section{REFERENCES}

Anochie-Boateng, J., Denneman, E., O'Connell, J. and Ventura, D. 2010. Hot-mix asphalt testing for the South African pavement design method. Proceedings of 29th Southern Africa transportation conference, Pretoria, pp 111-128.

Anochie-Boateng, J., O’Connell, T., Verhaeghe, B., and Myburgh, P. Development of a new asphalt mix design manual for South Africa. In Proceedings, Conference on Asphalt Pavements for Southern Africa, Sun City, South Africa, August, 2015.

ASTM C1252. "Standard Test Methods for Uncompacted Void Content of Fine Aggregate (as Influenced by Particle Shape, Surface Texture, and Grading)," ASTM International, West Conshohocken, PA, 5 pages.

Chesner, W. and R. Petrarca. Report on Glass Aggregate Pavement for the Browning Ferris Industries' Merrick Transfer Station Located in Hempstead, New York, August 1987

College of Engineering Texas Tech University, (1995). Uses of Glass Cullet in Roadway Construction. 01331-1. Texas, USA: Texas Department of Transportation, pp.16-18.

Federal Highway Administration Research and Technology, (n.d.). User Guidelines for Waste and By product Materials in Pavement Construction. www.fhwa.dot.gov[Accessed 26 Nov. 2015].

Flynn, Larry. "Glasphalt Utilization Dependent on Availability." Roads and Bridges, February 1993.

Hughes, C.S. 'Feasibility of using recycled glass in asphalt', Report No.VTRC 90-R3, Charlottesville, Virginia Transportation Research Council (1990)

Nash, P.T., Jayawickrama. P, Tock, R.W., Senadheera, S., Viswanathan, K., Woolverton, B. Use of Glass Cullet. In Roadway Construction: Laboratory Testing and Specification Development. Research Report Number 0-1331-2F, Texas DoT, Texas Tech University, 1995.

Recycled Materials Resource Center, (n.d.). Waste Glass - Asphalt Concrete. [online] Available at: http://rmrc.wisc.edu/ug-mat-waste-glass/ [Accessed 26 Nov. 2015].

Recycled Materials Resource Center, (n.d.). Waste Glass - Material Description. [online] Available at: http://rmrc.wisc.edu/ug-mat-waste-glass/ [Accessed 26 Nov. 2015].

SANS 3001-AG20. Civil Engineering Test Methods Part AG20: "Determination of the Bulk Density, Apparent Density and Water Absorption of Aggregate Particles Retained On the $5 \mathrm{Mm}$ Sieve for Road Construction Materials," Pretoria. www.sabs.co.za

SANS 3001-AG21. Civil Engineering Test Methods Part AG21: "Determination of the Bulk Density, Apparent Density and Water Absorption of Aggregate Particles Passing the $5 \mathrm{Mm}$ Sieve for Road Construction Materials," Pretoria. www.sabs.co.za 
SANS 3001-AG5. Civil Engineering Test Methods Part AG5: "Sand Equivalent Value of Fine Aggregates," Pretoria. www.sabs.co.za

Washington State Department of Trade and Economic Development, Glass Feedstock Evaluation Project, 1993. 